
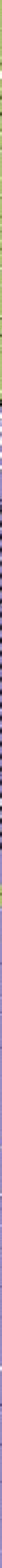


\title{
Embrapa e a cooperação científica internacional: do emparelhamento (catching-up) com a revolução verde à liderança tecnológica na agricultura tropical
}

\author{
Embrapa and the international scientific \\ collaboration: from Green Revolution \\ catching-up to technological leadership \\ in tropical agriculture
}

\author{
Petula Ponciano Nascimento* | Ana Célia Castro**
}

\begin{abstract}
Resumo
A criação da Empresa brasileira de Pesquisa Agropecuária (EMBRAPA), em 1973, consolidou um novo conceito para a pesquisa e inovação no Brasil, com base numa estratégia nacional para o desenvolvimento da agricultura. No final dos anos 1990, o Brasil já era reconhecido como líder internacional na agricultura tropical. No entanto, para permanecer na vanguarda, era necessária a realização de estudos prospectivos. Tratava-se de uma estratégia inovadora, na qual a Cooperação Internacional assumia um papel estratégico: a criação dos LABEX (Laboratórios do Exterior). Pretendemos reunir neste artigo as dimensões - institucional e organizacional - que permitem analisar a dinâmica do novo modelo de gestão para o desenvolvimento da pesquisa e da inovação na EMBRAPA. Foi possível constatar que, ao criar o Labex, a atuação internacional da Embrapa pretendia manter-se na fronteira tecnológica da agricultura tropical, o que exigia um esforço permanente. A continuidade dos Labex, no entanto, não se demonstrou duradoura. Novas prioridades de pesquisa institucional poderiam reconsiderar o seu papel.
\end{abstract}

Palavras-chave: Embrapa, Institucionalismo, Agricultura Tropical, Catching-up, Leapfrogging, Inovação Secundária.

\begin{abstract}
The creation of the Brazilian Agricultural Research Corporation (EMBRAPA), in 1973, established a new concept for research and innovation in Brazil, on the basis of a national strategy for the development of agriculture. In the late 1990, Brazil was already recognized as an international leader in tropical agriculture. However, to remain at the forefront, it was necessary to carry out prospective studies. The innovative strategy, in which international cooperation played a strategic role, was the creation of LABEX (International Laboratories). We plan to gather in this article the institutional and organizational dimensions - which allow us to analyze the dynamics of the new management model for the development of research and innovation at EMBRAPA. It had been realized that, to create the international performance Labex Embrapa intended to stay at the tropical agriculture technological frontier, which required an ongoing effort. Labex continuity, however, demonstrated a non-lasting strategy. New institutional research priorities could reconsider its role.
\end{abstract}

Keywords: Embrapa, Institutionalism, Tropical Agriculture, Catching-up, Leapfrogging, Secondary Innovation.

\footnotetext{
* Pesquisadora do Embrapa. https://orcid.org/0000-0003-2693-8892. E-mail: petulapn@gmail.com.

** Professora titular do Instituto de Economia, Universidade Federal do Rio de Janeiro. Vice-coordenadora do Instituto Nacional de Ciência e Tecnologia em Políticas Públicas, Estratégias e Desenvolvimento. https://orcid.org/0000-0002-7070-6047.E-mail: castro.anacelia@gmail.com
}

http://dx.doi.org/10.51861/ded.dmv.2.007 - Recebido em 11 de fevereiro de 2020. Aceito em 20 de maio de 2020. 


\section{INTRODUÇÃO}

O objetivo principal deste artigo é analisar a trajetória da EMBRAPA e seu aporte ao desenvolvimento científico e tecnológico da agricultura brasileira à luz da estratégia da cooperação científica internacional.

Os arranjos institucionais analisados, segundo o arcabouço conceitual escolhido, possibilitaram o desenvolvimento de projetos de pesquisa e transferência de tecnologia com alguns dos principais centros de pesquisa agrícola do mundo. Essa moldura conceitual pretende relacionar: o processo de emparelhamento tecnológico (catching-up); as possibilidades de ultrapassar fronteiras (leapfrogging); de introduzir inovaçôes secundárias (secundary innnovation $)^{1}$; e de ter em conta as coalizóes de interesses na agricultura brasileira.

$\mathrm{O}$ artigo possui características de um estudo de caso, pois foi realizado com base em uma pesquisa qualitativa exploratória com uso de entrevistas semiestruturadas, que deram suporte à investigação. A revisão de literatura realizada enfatizou os conceitos básicos da teoria econômica evolucionária, que nos auxiliaram a compreender a trajetória da EMBRAPA como organização. A segunda base conceitual foi o institucionalismo histórico, que nos guiou na análise da trajetória da empresa e suas relaçôes com ambiente institucional e com as políticas públicas.

Ao analisarmos os arranjos institucionais, verificamos que estes foram possibilitados no momento em que a EMBRAPA e o Sistema Nacional de Pesquisa Agropecuária (SNPA) puderam desenvolver projetos de pesquisa e de transferência de tecnologia com alguns dos principais centros de pesquisa agrícola do mundo. Desta forma, foi possível ter acesso a uma enorme variedade de material genético que pode ser trazido para o Brasil, testado, adaptado e validado.

O Brasil, assim como vários países em desenvolvimento, buscou um processo de inovação específico, onde o emparelhamento tecnológico começa com a aquisição de tecnologias no exterior para, posteriormente, adaptá-las às nossas necessidades e ao clima local. Em função de sua agricultura tropical e seus solos mais ácidos, a pesquisa precisou buscar manejos mais adequados e cultivares mais adaptadas ao meio ambiente, diferentes das oriundas de clima temperado.

A EMBRAPA pode ser enquadrada como um caso típico de catching-up e, posteriormente, de inovação secundária, e como exemplo temos o amplo processo de capacitação dos pesquisadores nos anos 70 e a integração com redes de pesquisa internacionais. Ao indagarmos se a cooperação internacional da Embrapa contribuiu para situar a empresa em uma nova fronteira da atuação científica e tecnológica podemos verificar que os 
resultados da primeira fase são claros. Dos temas dominantes nas negociações da cooperação internacional da Embrapa, o intercâmbio de germoplasma e de organismos vivos úteis para fins científicos foi um dos mais importantes e teve como resultados, não só a soja no cerrado, mas também novas sementes de forrageiras, a fixação biológica de nitrogênio que permitiu a redução de custos com fertilizantes nitrogenados, uma verdadeira revolução na agricultura tropical, entre muitas outras.

Este artigo busca, assim, analisar em que medida a Embrapa - na sua trajetória institucional - buscou reforçar a estratégia internacional, através de acordos de cooperação, parcerias e novos arranjos institucionais na área científica, e como essa estratégia influenciou a dinâmica da inovação tecnológica da agricultura brasileira.

\section{INOVAÇÃO INSTITUCIONAL: ESTRATÉGIA EMPRESARIAL A SERVIÇO DO SETOR PÚBLICO}

Em meados da década de 60 e início dos anos setenta, os preços dos alimentos dispararam como consequência da explosão das demandas interna e externa e a falta de resposta adequada da agricultura. A dívida externa começava a escapar ao controle da política econômica.

Sob a liderança do então ministro Delfim Netto decidiu-se que a política agrícola deveria preocupar-se com a produtividade da agricultura e com as exportações agrícolas. Por iniciativa do ministro Cirne Lima foi criado, no Rio de Janeiro, sob a administração da ABCAR, um grupo de trabalho para estudar porque a agricultura não respondia adequadamente aos estímulos de preços, mesmo com a expansão da fronteira agrícola.

O grupo rejeitou a hipótese da existência de um estoque de conhecimentos suficiente para o desenvolvimento e concluiu que era necessário investir pesadamente na geração de novos conhecimentos e na reformulação da pesquisa do Ministério da Agricultura. A criação de uma nova instituição de pesquisa foi proposta ao Ministro Cirne Lima, que a aceitou, sendo ela logo viabilizada no governo Garrastazu Médici pelo Ministro Delfim Netto.

Com base nesse diagnóstico inicial foram redesenhados os conceitos básicos para o desenvolvimento da pesquisa agropecuária no país, tendo como princípio básico que a seleção de prioridades de pesquisa seria realizada, em primeira instância, por um grupo de âmbito nacional e, à continuação, por outro grupo regional, ambos com representação de várias classes e que seriam guiados pelo princípio de orientar-se tendo em conta os problemas concretos da sociedade em geral. 
A demanda por pesquisa agropecuária foi considerada o principal problema e possuía dois componentes principais: a) a demanda atual; b) a demanda potencial ${ }^{2}$.

Em dezembro de 1972, o Congresso Nacional aprovou a criação de uma empresa pública, de direito privado, a EMBRAPA, para gerar a tecnologia que a modernização da agricultura requeria. $\mathrm{Na}$ época a decisão parecia inédita, e viria a ter enorme impacto na agricultura brasileira, como foi possível constatar nos anos que se seguiram. Interessante notar que o documento, ao descrever os princípios básicos que delineiam o novo esquema de orientação da pesquisa traz como primeiro princípio o da transferência de tecnologia, contudo não puramente sob o aspecto tecnológico, mas, sobretudo, sob a transferência de materiais e capacidades, como podemos observar nestes parágrafos do Livro Preto (1972, pags. 27-28):

"A questão da transferência de tecnologia, entretanto, tem vários aspectos. Um deles diz respeito à transferência de materiais, como, por exemplo, matrizes, equipamentos, sementes melhoradas, fertilizantes e defensivos, etc. Embora seja sempre difícil a transferência de materiais, há vários casos em que foi bem sucedida, como, por exemplo, o caso do "package" tecnológico para a avicultura, mecânica. A dificuldade de transferência de materiais, entretanto, não deve afastar a importância de se estudar a viabilidade de adaptação desses materiais às nossas condiçôes atuais. Isso nos leva ao segundo aspecto da questão de transferência de tecnologias que é a adaptação do "design". Aqui podem ser citados vários exemplos de materiais importados e que estáo sendo adaptados às condições brasileiras, é o caso de linhagens de milho híbrido, linhagens de trigo, o zebu, raças leiteiras e as variedades de café resistentes à "ferrugem”, etc. $\mathrm{O}$ aspecto mais promissor de transferência da tecnologia diz respeito à possibilidade de transferência de capacidades. Dentro deste aspecto estão incluídas as transferências do "know-how", o domínio de metodologias científicas para estudos de determinados problemas, a capacidade de execução de determinadas tarefas, etc.

Assim é que quando os programas de treinamento no exterior são estabelecidos e para lá seguem especialistas brasileiros, está se verificando nesse processo uma transferência, especialmente da metodologia da pesquisa, que poderá ser ajustada no caso do Brasil, como ocorreu com os pesquisadores treinados em genética que para aqui vieram empregando os métodos modernos para criar novas variedades.

A transferência dessas tecnologias implica numa poupança grande para a sociedade brasileira, pois os grandes custos envolvidos na pesquisa básica e aplicada para geração daqueles conhecimentos foram arcados por outras sociedades. Assim, a importação e adequação desses conhecimentos significam uma forma de maximizar recursos brasileiros para a pesquisa. É importante salientar que a transferência de capacidades é de grande relevância, também, para acelerar a transferência adequada de materiais e de "design"; a existência de um grupo ca- 
pacitado em saber o que transferir e como transferir é de fundamental importância para a função maximizadora acima mencionada.”

Podemos ver, na estratégia que foi desenhada, que os seus formuladores identificavam o atraso do Brasil em relação ao $\mathrm{P} \& \mathrm{D}$ dos países desenvolvidos e buscaram identificar açốes que pudessem reverter esse quadro, não só trazendo de fora a tecnologia existente, para buscar o processo de emparelhamento tecnológico (catching-up), mas também através de ações que ajudassem a desenvolver uma capacidade instalada no Brasil. Buscava-se aprender fazendo (learning by doing) com quem sabe, aprender as metodologias, e como disse o Dr. Eliseu na entrevista, "ser amigo de bancada, de casa, para que pudesse sacar o pulo do gato, aquilo que ninguém ensina” (ENTREVISTA, 2015).

O relatório fazia menção aos estudos da época, que abordavam as políticas científicas para o setor agrícola de países subdesenvolvidos, e que se encontravam em descompasso com o desenvolvimento, devido à escassez de produção de tecnologia e ao desperdício do pouco conhecimento existente. Não se dispunha nem de políticas definidas, e nem eram utilizados eficientemente os mecanismos de transferência de tecnologia.

Esse estudo também citava exemplos de alguns centros internacionais que, ao realizarem um trabalho mais sistematizado, mesmo com escassez de recursos humanos e financeiros, apresentavam resultados bastante positivos, tanto na produção de conhecimentos como no desenvolvimento de estratégias para a transferência de "packages" (pacotes) de práticas agronômicas.

Relacionava esse sucesso à metodologia que era utilizada nos trabalhos, mediante concentração de expertises, em grupos de trabalho interdisciplinares concentrando sua ação para a solução, de forma integrada, de problemas de produção de um ou mais produtos agrícolas, com suporte de infraestrutura logística para apoiar as atividades científicas.

Podemos verificar que a criação da Embrapa e do Sistema Nacional de Pesquisa Agropecuária (SNPA) foram um marco na modernização da agricultura brasileira, pois havia uma clara estratégia de curto, médio e longo prazo, com princípios, diretrizes e metas claras e bem definidas, onde a transferência de capacidades seria o diferencial. Ali estava o cerne do sucesso que anos depois foi colhido. O "Livro Preto" da EMBRAPA (1972, pags. 28-29) apontava:

"As formas mais usuais de transferir tecnologias, especialmente capacidade, são as seguintes: a) envio de técnicos brasileiros para treinamento no exterior; b) a contratação de técnicos estrangeiros para aqui estagiarem e realizarem pesquisas com equipes brasileiras. Esses dois processos vêm sendo utilizados no Brasil, mas não com a eficiência desejada. O principal fator parece ser a inexistência de critérios claros sobre prioridades de pesquisa, que realmente atendam aos problemas 
da sociedade brasileira, a transformação dessas prioridades em projetos viáveis de pesquisa. Existe uma terceira forma de transferência que vem se implantando no Brasil, que são os programas pós-graduados nas universidades, alguns em convênio com universidades, e que permitirão a formação de pesquisadores conhecedores dos critérios internacionais do procedimento científico, possibilitando acelerar o processo de transferência e também de criação de novas tecnologias e absorção do "know how" importado."

Desta forma, a nova estrutura de pesquisa a ser criada, no caso a Embrapa, nasce a partir de um planejamento estratégico, com um programa de açôes e metas bem delineadas, de processos já existentes e que foram readequados e potencializados, iniciando ali uma trajetória de inovação institucional que buscava o avanço tecnológico e, ao mesmo tempo, fortalecer uma dinâmica interna própria que levaria o Brasil a posicionar-se na fronteira do conhecimento e mesmo ultrapassá-la (leapfrogging).

O Brasil estava em vias de transitar de um setor agropecuário tecnologicamente atrasado para liderar o que se denominaria de agricultura tropical em menos de 15 anos. Como descrito por Contini et. al. (2010) a criação de uma empresa pública de direito privado, com maior flexibilidade e agilidade na gestão, com uma proposta de estrutura concentrada em pesquisa, valendo-se da capacitação de pesquisadores em centros de referência no Brasil e no exterior, e de uma infraestrutura dedicada à pesquisa, tinha como objetivo maximizar o tempo e o potencial da inteligência humana. Estas características, inerentes a uma organização orientada para a inovação, deveriam estar sempre presentes. Mendes e Albuquerque (2007) reforçam a tese de que a Embrapa tem apresentado um comportamento sistemático no desenvolvimento e implantação de inovaçôes organizacionais, desde a sua criação.

O processo de catching-up da economia brasileira, que inclui não só a indústria, mas também a agropecuária, inicia-se em meados da década de 40 e explode na década de 70, com o caso emblemático da soja, que demonstra a sinergia existente entre o sistema agroalimentar e industrial no processo de emparelhamento tecnológico. Este processo pode ser definido em duas grandes fases:

- A primeira vai do final da década de 40 até final dos anos 80 - onde predominam as instituições constitutivas da "revolução verde", o tripé pesquisa, extensão e crédito rural;

- E a segunda fase inicia-se nos anos 90 e continua em pleno curso até os dias de hoje, que está relacionada a questóes de desenvolvimento sustentável e economia de baixa emissão de carbono. ${ }^{3}$ 
Portanto, a modernização substancial da agricultura no Brasil, observada a partir da década de 70 e no início dos anos 80 , pode ser creditada ao resultado de políticas coordenadas, que levaram a um aumento da capacidade de pesquisa e desenvolvimento $(\mathrm{P} \& \mathrm{D})$ e aumento do volume de crédito, atrelado ao apoio das políticas de gestão de estoque, melhoria da distribuição e a comercialização de alimentos e produtos agroindustriais. Estas políticas coordenadas e os mecanismos de apoio levariam a uma melhor alocação de recursos, maior produtividade, melhor qualidade do produto e a redução de preços dos alimentos.

Esses resultados são destacados em documento, de 2012, do United States Departament of Agriculture (USDA), por Rada e Valdes, onde eles exaltam a mudança do setor agrícola brasileiro, que se transformou de um país que utilizava um sistema de produção agrícola tradicional, pouco intensivo em tecnologias, para um país que hoje detém uma posição de liderança mundial.

$\mathrm{O}$ estudo reafirma o acerto da estratégia adotada pelo governo brasileiro na década de 70 , através do modelo de substituiçãoo progressiva de importaçốes, aumento nos investimentos em ciência e tecnologia, com foco no desenvolvimento da pesquisa agropecuária.

\section{A COOPERAÇÃO CIENTÍFICA INTERNACIONAL E A EMBRAPA}

A Embrapa é uma Empresa Pública vinculada ao Ministério da Agricultura, Pecuária e Abastecimento, criada em 26 de abril de 1973, com a missão de "viabilizar a modernização e o crescimento da agropecuária, por meio da pesquisa tecnológica, da transferência do conhecimento, ao produtor rural e da extensão das fronteiras agrícolas”“ ${ }^{3}$. Nesta época, o modelo tecnológico que se difundia pela agricultura, por toda parte, era o da Revolução Verde, baseado no tripé pesquisa - assistência técnica crédito rural, e na difusão de um pacote de insumos modernos e máquinas característico deste paradigma, (CASTRO, 2007).

A pesquisa agrícola organizada no Brasil tem início do século 19, no Jardim Botânico do Rio de Janeiro, criado em 1808 por decreto-real do Príncipe Regente Dom João de Bragança (futuro Rei Dom João VI). Somente em 1859 foram estabelecidos os dois primeiros institutos de pesquisa agrícola: o Imperial Instituto Baiano de Agricultura (em novembro) e o Instituto Pernambucano (em dezembro), sendo este de vida efêmera. (CRESTANA \& SOUZA, 2008).

Durante esse período, os produtos agrícolas predominantes no Brasil eram o café e a cana de açúcar. No final século XIX, o Governo Imperial criou a Estação Agronômica de Campinas, um instituto federal que foi transferido 
para o governo do estado de São Paulo em 1891. Rebatizado como Instituto Agronômico de Campinas (IAC), e em pleno funcionamento até hoje, IAC é a mais antiga organização de pesquisa agrícola no país. (ALVES, 2010)

A Primeira Guerra Mundial, a crise econômica de 1929 e a Revolução Brasileira de 1930 levaram a mudanças substanciais na produção agrícola no país, até então concentrada em café e cana-de-açúcar, principais produtos de exportação. A pauta produtiva diversificou-se com o algodão, o milho, a laranja e outros alimentos que começam a ganhar expressão. Observou-se o aumento do apoio do governo para a agricultura na primeira metade do século 20, com a criação de institutos e agências como o Escritório de Cacau (1931), o Departamento Nacional do Café (1933), o Instituto do Açúcar e do Álcool (1931), o Instituto Nacional de Borracha (1942), entre outros. No entanto, a inovação agrícola ainda era limitada e a produção agrícola manteve-se concentrada em uma faixa estreita, ao longo da área costeira do Atlântico (ALVES, 2010).

A preocupação com uma agricultura mais moderna sempre esteve presente e, foi reforçada na "Carta de Teresópolis" em 1945, pelas classes produtoras, que sinalizaram quais deveriam ser os rumos da Política agrícola Nacional. Esse documento seria reforçado mais tarde pelo relatório da Comissão Mista Brasil-Estados Unidos, de 1949.

Segundo Castro, A.C. (1984), o relatório chamava atenção para a relação entre a continua elevação dos preços de alimentos e uma agricultura atrasada, com baixa produtividade e concentrada em poucas lavouras. "The future of Brazil's agriculture probably depends more on a sound and adequate agricultural research program then on any other one thing", (Comissão Mista Brazil-EUA 1949 apud CASTRO, A.C, P.316, 1984, 2007). O Relatório sinalizava, ainda, a necessidade de desenvolver o tripé pesquisa, assistência técnica e crédito rural e direcionava o desenvolvimento tecnológico rumo à denominada "Revolução Verde".

Mas, é somente na década de 1960 que se inicia a sistematização do processo de modernização do setor agrícola no Brasil. Em 1965, foram criados: o Programa Nacional de Crédito Rural, que forneceria financiamento para insumos e equipamentos modernos e a Política de Garantia de Preços Mínimos, que beneficiaria vários produtos agrícolas, melhorando o controle de estoque, comercialização e desenvolvendo sua logística.

No final dos anos 60, as discussóes propostas pelo Banco Mundial e outros órgãos multilaterais favoreceram a criação de uma base de inovação para agricultura, e inspirou no Brasil a futura criação da Embrapa. A Embrapa foi criada a partir de uma decisão governamental, com uma agenda estruturada e passível de ser executada, já visualizando uma ação 
consistente de capacitação internacional dos pesquisadores, com vistas à sua inserção na pesquisa, principalmente com apoio do governo americano, já parceiro do Brasil no setor agrícola.

Noinício década de 1970, no bojo do I Plano Nacional de Desenvolvimento (I PND), que tem entre seus objetivos colocar a ciência e tecnologia em prol dos grandes objetivos nacionais ${ }^{5}$, o governo cria o PROAGRO - Programa de Seguro Rural, a Empresa Brasileira de Pesquisa Agropecuária - Embrapa, e a Empresa de Assistência Técnica e Extensão Rural - Embrater. Os países industrializados estimulavam a produção intensiva de alimentos e o Brasil tentava equilibrar a sua balança comercial, por intermédio do crescimento das exportações de grãos, uma vez que a produção de commodities agrícolas era limitada ao café, cacau e algodão ${ }^{6}$. Para formar esta nova empresa era necessária a estruturação de um corpo técnico extremamente qualificado.

A Embrapa, os institutos de pesquisa vinculados ao extinto DNPEA (Departamento Nacional de Pesquisa e Experimentação Agronômica) e as universidades estaduais agrícolas passaram a fazer parte do Sistema Nacional de Pesquisa Agropecuária (SNPA), uma das maiores redes de pesquisa agropecuária do mundo tropical ${ }^{7}$.

Desta forma, foram enviados mais de duzentos profissionais, nos primeiros anos, para treinamento no exterior. ${ }^{8}$ A Embrapa escolheu, assim, uma estratégia que privilegiava a capacitação do seu corpo técnico nos centros internacionais de excelência em pesquisa agronômica, mas também em ciências humanas e sociais. $\mathrm{Na}$ década de 70 , a cooperação científica internacional foi considerada um dos pontos estratégicos para impulsionar a agricultura brasileira.

O Brasil atuava, neste período, como um país beneficiário (receptor) da cooperação internacional, no que diz respeito à política externa de cooperação para o desenvolvimento. Por intermédio do programa de capacitação da recém-criada Embrapa, os pesquisadores envolvidos com o tema tiveram acesso a cursos de mestrado e doutorado nas universidades americanas, com o intuito de potencializar os resultados das pesquisas adaptativas com a soja americana, como também estudos de produtividade e adequação a colheitas mecanizadas. Somente nos anos 80 as pesquisas se voltaram para temas mais ligados às questôes fitossanitárias.

Os resultados obtidos foram uma inegável conquista da pesquisa brasileira, com o desenvolvimento de cultivares adaptadas às baixas latitudes dos climas tropicais. Os pesquisadores brasileiros conseguiram superar a brecha tecnológica, desenvolvendo germoplasmas adaptados às condiçốes tropicais e viabilizando o seu cultivo, transformando, somente no 
Ecossistema do Cerrado, mais de 200 milhões de hectares improdutivos, em área potencial para o cultivo da soja e de outros grãos.

Podemos ver que o Brasil, assim como vários países em desenvolvimento, buscou um processo de inovação específico, ou seja, buscou a inovação endógena, onde o emparelhamento tecnológico começa com a aquisição de tecnologias no exterior para, posteriormente, adaptá-las às nossas necessidades e ao clima local. Entretanto, o processo de emparelhamento tecnológico é permanente, tendo em vista que a fronteira tecnológica se desloca sem cessar?.

Neste contexto, a atualização tecnológica adquire um ritmo acelerado e os países podem ser capturados por uma armadilha, onde o emparelhamento, rapidamente superado, produz uma situação em que o país ficaria de novo a reboque (falling behind) do ponto de vista tecnológico. ${ }^{10}$.

Para superar a armadilha tecnológica de países de renda média o processo de mudança do paradigma técnico passa a exigir que as empresas sigam o caminho denominado na literatura de inovação secundária" ("secondary innovation").

No caso da Embrapa, a produção de tecnologia era de caráter totalmente público, mas continha possibilidades de trajetórias tecnológicas que poderiam ser seguidas, mas que seriam adaptadas ao ecossistema tropical no qual estava inserida a agricultura brasileira. Partimos da seguinte hipótese: o Estado brasileiro criou condições para que a Embrapa, criada no início da década de 70 , exercesse um papel estratégico no processo de dinamização da mudança tecnológica da agricultura. A cooperação internacional sempre fez parte da dinâmica de crescimento e desenvolvimento da agricultura brasileira, seja na capacitação de recursos humanos, seja na potencialização dos recursos naturais e na consolidação de redes internacionais de pesquisa.

De fato, o Brasil vem definindo a fronteira do conhecimento na agricultura tropical de baixa emissão de carbono e de economia verde, através de uma agricultura conservacionista, de alta produtividade, apesar de não necessariamente o ter planejado nem ter seguido as recomendações de grandes think-thank, conforme observou Lopes (2012),

Reiteramos que este processo teve como base a aquisição de tecnologia por meio da capacitação de seus técnicos e da formação de redes com os países desenvolvidos. A mudança ocorre desde os seus primeiros anos de sua existência até meados da década de 80 . A busca para redução da brecha tecnológica, por meio da inovação secundária, parece ter sido a base do desenvolvimento de um trajetória tecnológica para a agricultura tropical brasileira renovada. 
Para vários dos entrevistados, a Embrapa se beneficiou, no início da década de 70, de um ambiente institucional que proporcionou condições favoráveis para o investimento em agricultura, com base na inovação tecnológica e institucional. A capacitação individual dos técnicos da empresa foi muito intensa nos anos 1970 e 1980, mas a fins dos anos 1990 uma nova estratégia começa a delinear-se. A prospectiva tecnológica institucionalizava-se com o estabelecimento de parcerias de dupla mão: a Embrapa representava os interesses brasileiros em tecnologias, produtos e processos no país de destino do Labex e, em troca, como reciprocidade, o Brasil contribuiria ao revelar processos e tecnologias de interesse deste parceiro. A parceria tecnológica de alto nível começava a tornar-se realidade.

Em 1998, a Embrapa cria seu primeiro laboratório virtual no exterior (Labex), nos Estados Unidos, com sede no Agriculture Research Service (ARS). Após essa experiência, foram criados os Labex`s Europa (Inglaterra, França, Alemanha, Holanda), Coreia e China, visando fomentar a articulação de redes e prospectar novos desafios tecnológicos, sendo o braço forte da cooperação científica, agora não apenas como receptora, mas também como parceira no desenvolvimento tecnológico para agricultura.

Percebe-se que novos desafios começam a se desenhar na atuação internacional da empresa e estes extrapolam o âmbito da cooperação científica e tecnológica. Complementarmente, a Embrapa busca desta forma novos horizontes e desafios com a finalidade de adequar-se à nova realidade da pesquisa agropecuária em nível internacional. Após a fundação da Embrapa e o envio dos técnicos para capacitação no exterior, a criação do Labex, em 1998 nos EUA, é considerada o grande marco que muda a relação na cooperação internacional, deixando de ser agente unicamente receptor da cooperação, passando a ser doador/receptor.

Em resumo, aqui estamos assinalando a existência de um novo ambiente institucional que favoreceu essas mudanças, bem como o amadurecimento da própria organização da empresa ao seguir uma estratégia interna e internacional ao mesmo tempo. Interessa revelar se, e em que medida, os resultados obtidos podem ser, de fato, atribuídos às duas dinâmicas.

Do ponto de vista conceitual pode ser importante revelar se a Embrapa vem fazendo uso do que se convencionou chamar de capacitaçóes dinâmicas (dynamic capabilities) $^{12}$, como ponto de partida e elemento central da estratégia de tornar a agricultura tropical brasileira um dos maiores casos de sucesso do mundo. Do ponto de vista da cooperação internacional, para além da cooperação científica e tecnológica, são relevantes o aprofundamento e o papel de liderança em questóes que vem sendo suscitadas e debatidas nos 
fóruns internacionais, o que se convencionou chamar de "diplomacia da

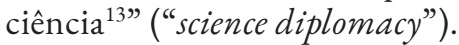

Finalmente, cabe indagar se existem estruturas institucionais e organizacionais adequadas ao dinamismo que se espera para a cooperação internacional em agricultura para o futuro, dada a relevância do tema.

\section{A DINÂMICA DA INOVAÇÃO NA AGRICULTURA - O ARCABOUÇO CONCEITUAL}

Desenvolvimento econômico brasileiro, liderança do Brasil no tema da agricultura tropical e importância do tema C\&T\&I na diplomacia brasileira são temas econômicos, complexos, mas que podem ser mais convergentes do que aparentam a princípio.

Para isso, apresentaremos, de forma breve, qual o arcabouço conceitual que vai nos permitir analisar a trajetória institucional da Embrapa na cooperação internacional científica, e como essa estratégia ajudou a superação da condição de país relativamente atrasado no setor agrícola, ao romper as barreiras tecnológicas impostas e alcançar o patamar atual no cenário internacional.

Começaremos então com a teoria econômica evolucionária e o institucionalismo histórico, que serão as principais lentes de análise, uma vez que estas teorias enfatizam a organização institucional da economia política, onde o Estado não é um agente neutro, mas estrutura os conflitos entre os grupos, numa arena política na qual ocorre a coalizão dos interesses em jogo.

Entretanto, estas teorias não são suficientes para analisar as hipóteses propostas. Os conceitos de emparelhamento tecnológico (catching-up), ultrapassar a fronteiras (leapfrogging), inovação secundária (secondary innovation) e capacitaçôes dinâmicas complementam a análise, como já apontamos.

Partindo do pressuposto de que instituiçôes, organizaçóes e arranjos institucionais são fundamentais para que o Estado possa operacionalizar a sua agenda de política pública, incluímos aqui a política externa ${ }^{14}$, que no modelo de tomada de decisóes e gestão estratégica, as empresas buscam relacionar temas como concorrência, inovação competitividade, decisóes sob incerteza, comprometimento e impacto econômico (Burlamaqui \& Proença, 2003).

A diversidade e riqueza de atores que interagem para criar as condiçóes favoráveis, o ambiente institucional necessário para o salto tecnológico, as conjunturas críticas e os processos de longo prazo, conformam a abordagem institucionalista em sua vertente histórica. 
No caso da cooperação científica internacional da Embrapa verificaremos que por ser uma empresa pública precisava negociar, em diversas instâncias, sendo a principal o seu Conselho de Administração (CONSAD), que é constituído por um representante do Ministério da Agricultura, do Ministério da Fazenda, Ministério do Planejamento e representante do setor privado.

Nessa instância foram tomadas as decisões que levariam à aprovação de medidas para a implementação de várias ações, entre elas o modelo de cooperação internacional, que primeiramente esteve fortemente centrado na capacitação de pesquisadores. Ao final dos anos 90, o modelo foi sendo ampliado com a implantação dos escritórios virtuais no exterior, o que favoreceu o salto alcançado pelo setor agropecuário nos anos 90 e manteve a trajetória de inovaçóes nos anos subsequentes. De uma estratégia de emparelhamento tecnológico (catching-up) transitava-se para a fronteira do conhecimento na agricultura.

As condições institucionais induzem determinadas trajetórias e, no caso da Embrapa, podemos perceber como é importante a análise histórica do ambiente institucional. $\mathrm{O}$ direcionamento dado fez e faz parte de uma ação vinculada à política nacional de ciência, tecnologia e inovação, à política agrícola e, podemos talvez acrescentar, à política externa brasileira. Hall e Taylor (2003) enfatizam que as instituiçóes e organizaçóes se combinam para dar forma não somente às políticas governamentais, mas também às estratégias e alianças dos grupos de interesse.

Recentemente, a abordagem do institucionalismo histórico tem acumulado um conhecimento amplo, tratando de questóes importantes como a interseção entre política doméstica e internacional, transições democráticas, entre outros temas (Pierson e Skocpol, 2008).

Para iniciar esta análise $\mathrm{e}^{15}$, adotaremos um dos princípios da teoria econômica evolucionária, pano de fundo para analisar os fenômenos resultantes da inovação institucional por parte das organizaçóes. Essa teoria assume que o capitalismo é um processo dinâmico e histórico, que determina os padrốes de comportamento da firma e os resultados dos mercados ao longo do tempo. (NELSON \& WINTER, 1982). As análises de estratégia e estruturas de mercado definem a trajetória da empresa (NELSON \& WINTER, 1982; POSSAS et al. 1996), ajudando a compreender o processo de criação da Embrapa e a evolução da cooperação internacional, bem como as suas adequaçóes ao longo do tempo. Sob a lente da análise de Nelson este movimento é descrito como um processo evolucionário, que apresenta duas características importantes: a incerteza, e o caráter parcialmente público da tecnologia ${ }^{16}$. As inovaçóes modernizaram setores da economia e até mesmo 
apoiaram a criação de novos setores, o que levou o Brasil a mudar seu patamar no ambiente competitivo global nos anos 90 , no setor agropecuário, tendo como base uma ferramenta estratégica da cooperação internacional.

Coriat e Weinstein (2002) reúnem as dimensões institucional e organizacional para analisar a inovação no âmbito da firma. A complementaridade dessas abordagens nos auxilia na compreensão da trajetória da Embrapa no que diz respeito à cooperação internacional e à consolidação do seu papel como importante ator na pesquisa agropecuária mundial. A abordagem organizacional é relevante para entender como as mudanças estrutural e organizacional permitiram que a Embrapa construísse um ambiente adequado à inovação, não só no âmbito cientifico e tecnológico, mas também institucional.

Afinal, as instituições, segundo Hodgson (2006), costumam encarnar-se em organizações competentes e coordenadas, com regras formais e com capacidade de impor sanções coercitivas, como o governo ou empresas. O núcleo duro da análise e da formulação de políticas deve ser, então, a interação entre instituições, inovação e a estratégia organizacional.

A análise e a formulação de políticas tecnológicas, por outro lado, devem ter em conta a interação entre instituiçôes, inovação e as estratégias organizacionais (CASTRO, 2004). A arquitetura e a estrutura institucional são fundamentais para que possamos compreender a trajetória da Embrapa e a sua evolução no âmbito da cooperação internacional.

Podemos entender que a Embrapa, como empresa pública, criada para coordenar o Sistema Nacional de Pesquisa Agropecuária (SNPA) e garantir o dinamismo do setor agrícola brasileiro, alcançou a primazia tecnológica em Agricultura Tropical. As abordagens institucionalista e organizacional são fundamentais para essa análise.

\section{Catching-up, Leapfrogging e Inovação Secundária}

No caso da cooperação internacional e de sua interface com a dinâmica da inovação na agricultura, como já sinalizamos, serão necessárias outras bases conceituais para compreender por que a Embrapa adotou essa trajetória. Desde já sabemos que as condiçóes institucionais foram fundamentais para que isso ocorresse. A Embrapa, apesar de ser uma empresa, representa não apenas uma organização, mas também uma instituição, uma vez que incorpora atividades de coordenação de Sistema Nacional de Pesquisa Agropecuária (SNPA), além de atuar ativamente na formulação das políticas públicas. ${ }^{17}$ 
Até hoje um dos principais exemplos de catching-up do Brasil na agropecuária é a soja. As transformações produtivas e tecnológicas que acompanham os processos de cachting-up ocorrem em certa medida, vinculadas a alguma mudança social e costumam ter traços comuns de outras experiências históricas. Acreditamos que, no caso da Embrapa, a análise da sua estruturação e das suas decisóes estratégicas vai nos mostrar o processo de evolução da inovação na agricultura, vinculado à cooperação internacional, por intermédio do acesso às grandes redes científicas internacionais.

Será interessante ver como na segunda metade dos anos 1990, o processo de cachting-up se aproxima dos processos globalizados, e como a Embrapa adota uma nova estratégia para manter-se na fronteira do conhecimento. ${ }^{18}$ $\mathrm{O}$ caso da soja pode ser aqui exemplificado como superação dos efeitos esperados, uma vez que, além do emparelhamento tecnológico com os Estados Unidos e Argentina, deslocou as fronteiras agrícolas para o centrooeste e o centro-norte.

O Brasil, assim como vários países em desenvolvimento, buscou um processo de inovação específico, ou seja, buscou a inovação endógena. O processo, como enfatizamos, se inicia com o emparelhamento tecnológico a partir da aquisição de tecnologias no exterior para, posteriormente, adaptálas às nossas necessidades e ao clima local. Em função de sua agricultura tropical e seus solos mais ácidos a pesquisa precisou buscar manejos mais adequados e cultivares mais adaptadas ao meio ambiente, diferentes das oriundas de clima temperado.

A Embrapa pode ser entendida, além de um caso típico de catching-up, como um exemplo de inovação secundária. $\mathrm{O}$ amplo processo de capacitação dos pesquisadores nos anos 70 e a integração com redes de pesquisa internacionais, num momento em que a ciência já era vista de forma cada vez mais multidisciplinar, consolida-se no Brasil, com grande participação da Embrapa, o período denominado de "Revolução Tropical"19 (CRESTANA \& SOUSA, 2008)

Xiaobo Wu et al. (2013, p. 03) definem inovação secundária como um específico processo de inovação, especialmente em países em desenvolvimento, que se inicia com a aquisição de tecnologia de países desenvolvidos, ou através de contratos de transferência tecnológica. As empresas desenvolvem as tecnologias adquiridas seguindo trajetórias existentes dentro do mesmo paradigma tecnológico estabelecido, aproveitando suas capacidades próprias, através de um processo original de inovação ${ }^{20}$.

A inovação secundária caracteriza-se pelo desenvolvimento de tecnologias cuja trajetória ainda não está consolidada internacionalmente. A estratégia da Embrapa pode ser analisada a partir deste modelo, uma vez que o salto 
tecnológico obtido pode explicar-se pela adaptação eficaz das tecnologias internacionais às condiçóes de clima tropical, o que poderia ser considerado o "pulo do gato" da pesquisa agropecuária nacional.

O ciclo típico de inovação secundária possui cinco estágios: aquisição, assimilação, melhoria, crise e renovação. O pós-inovação secundária requer altos níveis de capacitação em $\mathrm{P} \& \mathrm{D}$, de produção avançada que pode ser considerada como o nível mais alto de inovação secundária, a partir de uma base de tecnologias adquiridas. O limite do processo de inovação secundária, o momento de crise, é estabelecido pelo nível das capacitaçóes nacionais: nesse ponto ou se depara com a armadilha tecnológica dos países de renda média, ou o país ultrapassa o limite e passa a exercer liderança tecnológica internacional. Entretanto, não há garantias de que possa gerar e desenvolver um padrão tecnológico novo ${ }^{21}$.

O modelo da inovação secundária, baseado nas práticas de inovação das empresas chinesas, destaca o papel significativo da construção do conhecimento e da inovação, e abre a caixa preta do processo organizacional, tanto para o aprendizado dinâmico, quanto para o acúmulo de conhecimento e a construção de competências. A estratégia de enviar pesquisadores ao exterior e desenvolver novas cultivares adaptadas ao clima tropical, com tecnologias próprias para o Brasil, poderia ser considerado um exemplo. ${ }^{22}$

\section{Capacitações Dinâmicas}

A Embrapa é uma empresa pública de C,T\&I em agricultura que conquistou uma sólida reputação ao longo dos seus quarenta e sete anos (2020) e construiu, ao longo de sua trajetória, capacidades necessárias para sustentar uma performance superior em uma economia aberta, com rápida inovação, originada de fontes globalmente dispersas e com certa capacidade de produção.

O conceito de capacitaçóes dinâmicas enfatiza o processo de sentir e capturar as oportunidades, como uma meta capacidade, tanto das organizaçôes em geral quanto das empresas em particular. A abordagem das capacitaçôes dinâmicas é uma construção teórica da década de 1990, no entanto, originalmente foi introduzida por Sidney G. Winter (1964), em seu artigo intitulado: Economic "Natural Selection and the Theory of the Firm". ${ }^{23}$

$\mathrm{O}$ artigo de Teece, Pisano e Shuen ultrapassa a perspectiva da Visão Baseada em Recursos (VBR). A VBR, segundo os autores, não teria sido capaz de explicar como empresas bem-sucedidas demonstram capacidade de resposta à competitividade e, sobretudo, capacidade de gestão para efetivamente coordenar e reimplantar competências internas e externas. (Teece e Pisano, 1994 e Teece Pisano e Schuen, 1997). 
Teece et al. (1997) denominam capacitações:

- Os distintos processos, procedimentos, estruturas organizacionais, habilidades, regras de decisão, disciplinas.

- Capacidades que habilitam as empresas a criar, utilizar e proteger os ativos intangíveis que suportam uma performance superior de longo prazo.

As capacitações dinâmicas para Teece et al. (1997), referem-se à habilidade de integração das firmas, de construção, e de reconfiguração das competências internas e externas para se adaptar rapidamente às mudanças do ambiente. Uma das questôes mais importantes deste trabalho é saber de que maneira, através da definição de estratégias, a empresa alcança e sustenta a vantagem competitiva frente a outros países, em momentos de rápida mudança e de desafios complexos.

Para Teece, (2009) o conceito de capacitações dinâmicas apresenta algumas das vantagens para a empresa:

- “... se uma empresa possui recursos e competências, mas a ela falta capacitaçóes dinâmicas, esta empresa tem a chance de gerar retorno competitivo por um curto período, mas retornos superiores não serâo sustentáveis, exceto ao acaso". (Teece, 2009, p. 87).

- "Empresas com fortes capacitações dinâmicas são intensamente empreendedoras. Elas não apenas se adaptam ao 'ecossistema' dos negócios, mas também os conformam através de inovação e colaboração com outras empresas, entidades e instituiçôes”. (Ibid., p. 3-4).

Podemos resumir que, por Capacitaçôes Dinâmicas (Dynamic Capabilities) entende-se "capacitaçóes" (capabilities) como habilidades especificas da organização como um todo ou de suas partes (PROENÇA, 2003). Na percepção da E. Penrose (1959. P.25) as capacitaçốes são recursos relevantes, porque, no limite, a mera disponibilidade de um determinado ativo na empresa não significa que isso gere um potencial resultado. Apesar do conceito de Teece ter sido pensado para empresas ele se revela robusto para organizaçóes do setor público.

O capital intelectual da empresa é considerado o seu bem mais precioso e a inovação é um dos seus alicerces, seja no âmbito da geração de novas tecnologias seja na sua estrutura organizacional. As principais conquistas e contribuiçôes da Embrapa e do SNPA para a agricultura tropical, nos últimos 40 anos, podem ser resumidas nos seguintes temas:

- Agricultura de Cerrado;

- Cultura da soja (fotoperiodismo); 
- Fixação biológica de nitrogênio;

- Integração lavoura-pecuária-floresta;

- Controle de doenças e pragas para agricultura tropical;

- Fibras e Madeiras (algodão e eucalipto);

- Biotecnologia e nanotecnologia;

- Animais e Plantas tropicalizados.

\section{A Diplomacia Científica}

Há uma nova tendência que está emergindo sob a égide da "diplomacia científica”, e que vai além da negociação de grandes projetos internacionais de C\&T ou de cooperação de P\&D das empresas. Ela abrange questóes de política externa, na interface com a ciência e a tecnologia, tais como as posições do Brasil na OMC, assim como a proposta que o Brasil levou para a Conferência das Partes da Convenção do Clima (COP), com o objetivo de reduzir as metas de emissão de gases causadores de efeito estufa. ${ }^{24}$

Portanto, a evolução da atuação internacional da Embrapa não pode prescindir de uma análise da sua composição e de sua estratégia no exterior que inclua o que atualmente se convencionou chamar de "diplomacia da ciência" ("science diplomacy"). Foi possível constatar que, ao criar o Labex e fortalecer a sua atuação internacional a Embrapa considerou que, uma vez que a empresa atingiu a fronteira do conhecimento no cenário cientifico junto aos demais pares na agricultura tropical, a manutenção na fronteira exigira um esforço de prospecção permanente, e que um dos instrumentos para viabilizar essa ação com poucos custos internos, e com características mais sistêmicas e de longo prazo, seria a continuidade dos Labex`s.

A Embrapa explorou um novo conceito institucional, de parceria internacional, ao criar o modelo Labex, ou seja, laboratório externo, virtual ou "sem muros". No âmbito da atuação internacional da Embrapa, o modelo Labex fez parte da cooperação científica desenvolvida pela Embrapa, que atuou de forma bem distinta da cooperação técnica.

Neste arranjo, os pesquisadores seniores monitoram o avanço da ciência em todo o mundo, identificam tendências e atividades científicas que atendam os interesses comuns da Embrapa e do parceiro e a partir disso, articulam a realização de ações conjuntas de $\mathrm{P} \& \mathrm{D}$ e de transferência de tecnologia de interesse da agricultura brasileira e do país que hospeda o Labex. ${ }^{25}$.

Existe um certo consenso de que ingressamos na chamada "Economia Verde" ou "Crescimento verde", no qual as tecnologias estão presentes para garantir o desenvolvimento sustentável. Desta forma, há uma nova tendência emergente sob a égide da "diplomacia científica", que vai além da negociação de grandes projetos internacionais de C\&T ou de cooperação entre 
empresas. Ela abrange questões de política externa, na interface com a ciência e a tecnologia. ${ }^{26}$ Percebe-se que os novos desafios começam a desenhar-se na atuação internacional da empresa e estes extrapolam o âmbito da cooperação científica e tecnológica.

\section{CONCLUSÕES}

Chegamos a um momento histórico singular no qual a complexidade e aceleração da pesquisa agrícola internacional gera incertezas para um país que deseja manter-se na fronteira tecnológica. Neste cenário os problemas e desafios sugerem abordagens multidisciplinares e cooperação internacional. A análise de como foram utilizadas as ferramentas que ajudaram a construir essa trajetória de sucesso, no caso da cooperação internacional, e como ela ainda pode ser relevante e estratégica para a consolidação dessa trajetória, pode ajudar a Embrapa e o país a evitarem a armadilha tecnológica dos países de renda média.

No caso da agricultura brasileira foi possível identificar uma maior interação da $\mathrm{P} \& \mathrm{D}$ com as políticas públicas que apoiaram várias decisões do Brasil junto à OMC. Mais importante talvez tenha sido a autorização e suporte do governo brasileiro à criação dos Labex ${ }^{27}$, no final da década de 90, como forma de buscar novas fronteiras do conhecimento e da inovação no setor.

São ações como esta que podem ser caracterizadas como uma nova abordagem de política orientada por missóes ${ }^{28}$, focadas em inovação, e que levam a interaçóes positivas entre o Estado, o setor empresarial e a academia. Trata-se de desenvolver, implantar e monitorar uma política de inovação estratégica baseada nos pontos fortes do sistema de inovação, para superar as fragilidades do país e enfrentar seus desafios, aproveitando as oportunidades oferecidas por uma nação vasta e rica. Aqui podemos ver que, apesar de estratégico para a empresa, essa agenda não tem sido devidamente considerada pelo governo federal ${ }^{29}$.

Por isso, além da importância para os estudos sobre desenho organizacional e institucional do setor público, com impacto direto em políticas públicas, o estudo de caso sobre a Embrapa pretendeu ser relevante, na medida em que possibilita uma reflexão sobre os rumos da liderança brasileira em agricultura tropical no mundo, e como o Estado brasileiro vai utilizá-la e projetá-la nos próximos anos. 


\title{
Notas
}

\begin{abstract}
${ }^{1}$ Xiaobo Wu, Rufei Ma, Guannan Xu (2013).
${ }^{2}$ A demanda atual se manifesta por intermédio das solicitações governamentais, das solicitações dos industriais vinculados aos produtos agrícolas, especialmente da agroindústria, dos serviços orientados para a agricultura, como, por exemplo, serviços de extensão, e dos agricultores em geral. A demanda potencial pode ser visualizada mediante os projetos em longo prazo do Governo, das tendências do campo científico determinado, da intuição dos pesquisadores a respeito das tendências da economia brasileira e ainda das experiências vividas por outros países nos campos considerados.
\end{abstract}

${ }^{3}$ Castro, Ana Célia - The catching-up of the brazilian agrifood system: National development strategies, institutions and firms. Anais do XXXV Encontro Nacional de Economia [Proceedings of the 35th Brazilian Economics Meeting], 2007.

${ }^{4}$ CABRAL, J. Irineu. Sol da Manhã: memória da Embrapa. 1 ed. Brasília: UNESCO, 2005, p.11.

${ }^{5}$ Castro (1984, p.334). Cabral (2005).

${ }^{6}$ A pesquisa agronômica sistemática no Brasil data de, pelo menos, o final do século XIX, com o Instituto Biológico de Campinas, caso não se tenha em consideração a pesquisa relacionada com o ciclo da canade-açúcar, desde a época colonial. Institutos como o Agronômico de São Paulo, o IPARDES, no Paraná, e o antigo Sistema Nacional de Pesquisa Agropecuária (SNPA) antecedem a fundação da EMBRAPA, em 1973.

${ }^{7}$ Alves (2010) e Castro (1984)

${ }^{8} \mathrm{O}$ exemplo mais emblemático é o caso da soja. Até o final dos anos 60 , a pesquisa com a cultura da soja no Brasil era incipiente e concentrava-se na Região Sul do País, atuando, fundamentalmente, na adaptação de tecnologias, com variedades, introduzidas, principalmente, dos EUA.

${ }^{9}$ Existe uma peculiaridade característica da agricultura tropical, que é a necessidade de adaptar sementes e cultivares às condições locais, especialmente por conta do fotoperiodismo, que acelera a maturação dos cultivos, e da natureza diversa do solo tropical, cujo manejo deve ser diferente do que é adequado aos solos no clima temperado.

${ }^{10}$ Amsden, (2001); Castro, A.B (2003); Castro, A.C (2007). Segundo Castro, A.C (2007, p.02) "On the contrary of the usual view, there was a catching-up process in the Brazilian agribusiness system during the second half of the twentieth century. Not only was the growth intense, but new technological processes had been introduced".

${ }^{11}$ De forma muito sintética, quando a trajetória tecnológica em um determinado setor não está ainda estabelecida, os países podem testar rotas alternativas que os levarão (ou não) à superação dos obstáculos da sua própria capacitação tecnológica. Xiaobo Wu et. al, (2013).

12 Capacitações dinâmicas (dynamic capabilities) - entende-se por "capacitações" (capabilities) as habilidades especificas da organização como um todo ou de suas partes (Proença, 2003). Na percepção da E. Penrose (1959. p.25) as capacitações são recursos relevantes, porque, no limite, a mera disponibilidade de um determinado ativo na empresa não significa que isso gere um potencial resultado. Os serviços providos pelos recursos são uma função da maneira como são utilizados, pois os mesmos recursos, quando usados para diferentes propósitos, ou de formas diferentes, ou em combinações diferentes com outros recursos, podem gerar um conjunto completamente diferente de produtos e serviços. Trata-se da ideia de habilidades estáveis para gerar inovações. (D. Teece, G.Pisano e A. Schuen, 1997). Referem-se às habilidades associadas à inovação dentro da firma das quais fazem parte também, o desempenho da empresa ao criar e desenvolver novos produtos, processos e rotinas, e responder de forma eficaz e eficiente a mudanças do ambiente.

${ }^{13}$ Diplomacia da Ciência ou "Science diplomacy" é descrito pelo estudo do "The Royal Society" (2010) como um conceito fluido que pode ser aplicado ao papel da ciência, tecnologia e inovação em três dimensões da política: (a) informando objetivos de política externa com os pareceres científicos (science in diplomacy/ciência na diplomacia); (b) facilitando a cooperação científica internacional (diplomacy for science/diplomacia para a ciência) e (c) utilizando a cooperação científica para melhorar as relações internacionais entre países (science for diplomacy/ciência para a diplomacia).

${ }^{14}$ Nesta tese assumimos a política externa como uma política pública, como diz Milani e Pinheiro (2013), trazendo-a para o terreno da politics, ou seja, reconhecendo que sua formulação e implementação estão inseridas na dinâmica das escolhas de governo que, por sua vez, resultam de coalizões, barganhas, disputas, acordos entre representantes de interesses diversos, que expressa, enfim, a própria dinâmica da política.

15 Como já foi dito anteriormente, quando a Embrapa foi criada no início dos anos 70 o contexto da pesquisa agropecuária apresentava-se dispersa, de baixo impacto, com uma agricultura incipiente e maior parte do território brasileiro identificado como inadequado para produção agrícola. Para entender como saímos deste patamar ineficiente para ser o País com o maior potencial agropecuário do mundo os conceitos de catching-up, leapfrogging e inovação secundária, associados às teorias anteriormente mencionadas, vão integrar as lentes que nos permitem ler a história da cooperação científica da Embrapa sob uma nova ótica. 
${ }^{16}$ No caso da Embrapa trata-se da produção de tecnologia de caráter público, mas com distintas trajetórias tecnológicas que podem ser reveladas. As escolhas refletem a adaptação ao ecossistema tropical em que estava inserida a agricultura brasileira.

17 Exemplo dessas políticas são a elaboração de medidas mitigadoras para a emissão de gases de efeito estufa, a lei sobre o código florestal, entre outras.

18 "Ao avançarmos para a segunda fase, o catching-up deve ser estudado, cada vez mais, à luz dos processos de globalização em curso, na disputa pela competitividade em mercados internacionais, a partir de novas convenções, tendo em conta as instituições de governança global, os bens públicos globais cuja oferta é sua missão prover, com foco na transformação produtiva e no desenvolvimento regional e nacional". (Castro 2004, p. 5).

${ }^{19} \mathrm{Na}$ Revolução Tropical sementes e máquinas foram adaptadas, a erosão foi controlada, importou-se e foram desenvolvidas técnicas de agricultura conservacionistas, notadamente o cultivo mínimo e o plantio direto na palha, e as fronteiras foram expandidas para o interior das savanas tropicais dos Cerrados. Um exemplo que ilustra muito bem este processo foi a introdução e o desenvolvimento de nossa principal cultura comercial: a soja e a expansão da agricultura nos solos ácidos do cerrado brasileiro.

20 Segundo a OCDE (2010), a inovação científica e tecnológica pode ser considerada como a transformação de uma ideia em um novo produto, um produto melhorado, um novo processo operacional ou melhorado, a ser utilizado nas diversas atividades públicas e/ou privadas ou em uma nova prestação de um serviço social.

${ }^{21}$ Podemos ver a diferença entre o modelo de aprendizagem tecnológica tradicional e o modelo de inovação secundária. Este enfatiza as inter-relações e interações fundamentais entre as tecnologias adquiridas com as tecnologias locais e o ambiente de negócios do mercado.

22 O caso da soja, como já foi dito, que teve sua tecnologia adaptada para a região tropical e sua importância para a agricultura brasileira, poderia ser inicialmente considerado um exemplo de catchingup e de leapfrogging - ao ultrapassar a fronteira tecnológica dos países em desenvolvimento e passar a desenvolver sua própria tecnologia para agricultura tropical - alterando para isso seu modelo de P\&D. Ao realizar essa trajetória consolida um processo de inovação secundária. O modelo analítico da inovação secundária permite entender o sistema de aprendizagem, inovação e a capacidade dinâmica da agricultura brasileira. Esta ferramenta analítica pode revelar a capacidade de aprendizado de uma organização, e a relação com a mudança tecnológica em países em desenvolvimento.

${ }^{23}$ A conjugação entre incerteza sobre o futuro e o peso de um passado glorioso está no âmago da complexidade das decisões estratégicas, por parte de qualquer empresa e, principalmente, da Embrapa, considerada a maior empresa de pesquisa em agricultura tropical do mundo. A Embrapa é uma empresa de excelência, com capacitações dinâmicas mobilizadas para gerar inovações, e que continua a investir nas capacidades dinâmicas individuais e da organização para se manter como a maior empresa de pesquisa do mundo em agricultura tropical e para buscar estar à frente dos novos cenários que se desenham.

${ }^{24}$ Lopes (2010).

${ }^{25}$ Tendo sido o primeiro Labex implantado em parceria com o ARS, nos EUA, em 1998, os interesses seriam do Brasil e dos Estados Unidos.

${ }^{26}$ Crestana $(2011,2014)$ e Lopes (2012) identificaram que o aumento da capacidade científica e de inovação das potências emergentes criam não só a concorrência, mas novas oportunidades para sinergias entre países, que percebem que devem criar mecanismos mais eficazes para a mobilização de sua capacidade por intermédio de redes internacionais.

${ }^{27}$ Os Labex 's tinham como meta fortalecer a cooperação internacional e passar do patamar de adaptação de tecnologias ao clima dos trópicos (inovação secundária) à geração de pesquisa e inovação - não só para os ecossistemas tropicais mais também de clima temperado. Nestes ecossistemas os insumos e recursos naturais enfrentam os desafios - para a pesquisa brasileira em agricultura - do desenvolvimento sustentável.

${ }^{28}$ Para Mazzucato e Penna (2016), as Políticas "mission-oriented" (orientadas por missões) podem ser definidas como políticas públicas sistêmicas na fronteira do conhecimento para atingir metas específicas ou "big science deployed to meet big problems" ("a grande ciência para enfrentar os grandes problemas").

${ }^{29}$ Este livro desmascara o mito do Estado como um paquiderme burocrático, sem mobilidade e ineficiente como gestor de negócios. Para muitos, o Estado deveria apenas corrigir as "falhas de mercado", deixando a inovação e o empreendedorismo para o dinâmico setor privado. No entanto, dos produtos mais inovadores da Apple até as chamadas tecnologias "limpas", passando pela indústria farmacêutica, Mazzucato mostra que o setor privado só aposta depois do Estado Empreendedor ter feito todos os investimentos mais ousados e de maiores riscos. O governo brasileiro não parece considerar a importância estratégica do investimento contínuo em C,T\&l, uma vez que a continuidade dos investimentos fica ameaçada quando se depara com a questão orçamentária (Mazzucato, 2014). 


\section{Referências}

ALVES, E. Um caso bem-sucedido de Inovação Institucional. Revista de Política Agrícola. Ed. Especial, Julho, p. 65-73. Brasília-DF, 2010.

\begin{abstract}
AMSDEN, A. The Rise of "the Rest": challenges to the West from dateindustrializing economies. New York, Oxford University Press. Set. 2001.

BESKOW, P. R. O crédito rural público numa economia em transformação: estudo histórico e avaliação econômica das atividades de financiamento agropecuário da CREAI/BB, de 1937 a 1965. Tese (doutorado), UNICAMP - Instituto de Economia, Campinas, SP, maio 1994. BURLAMAQUI, L; PROENÇA, A. Dinâmica Estratégica e Teoria Econômica: Estratégia Empresarial no Contexto da Economia Evolucionária. Encontro Anual da Associação Nacional dos Programas de Pós-Graduação em AdministraçãoENANPAD, XXVII, 2003.
\end{abstract}

CABRAL, J. I. Sol da Manhã: memória da Embrapa.1 ed. Brasília: UNESCO, 2005. $346 \mathrm{p}$.

CASTRO, A. B. El segundo catchupbrasilenõ. Caracteristicas $Y$ Limitaciones. Revista de la Cepal, n. 80, ago. 2003.

CASTRO, A. C. O Catching-up do sistema agroalimentar brasileiro: Fatos estilizados e molduras conceituais. $31^{\circ}$ Encontros anual da ANPOCS, Caxambu/MG, 2007. 35 p. . Construindo Pontes: Inovações,

Organizações e Estratégias como Abordagens Complementares. Revista Brasileira de Inovação. Rio de Janeiro, v.3, n. 2, p. 449- 473, jul./dez., 2004.

. Ciência e Tecnologia para a agricultura: Uma análise dos planos de desenvolvimento. Cadernos de difusão de tecnologia, EMBRAPA, Brasília, v.1, n 3, p. 309-344, set/dez., 1984.

CONTINI, E; GASQUES, J. G; Alves, E; BASTOS, E. Dinamismo da Agricultura Brasileira. Revista de Política Agrícola. Ed.
Especial, Julho 2010. Pág 65-73. Brasília-DF, 2010.

CORIAT, B., WEINSTEIN, O. Organizations, firms and institutions in the generation of innovation. Research Policy, n. 31, p. 273-290, 2002.

CRESTANA, S. Relatório do seminário preparatório «Internacionalização da inovação brasileira». Parcerias Estratégicas (Brasília), v. 15, p. 269-281, 2010. . Relatório da sessão «O Brasil na nova geografia global». Parcerias Estratégicas (Brasília), v. 15, p. 283-294, 2010.

CRESTANA, S., SOUSA, I. Agricultura Tropical no Brasil. In: Agricultura tropical: quatro décadas de inovações tecnológicas, institucionais e políticas V.I - Editores técnicos. Albuquerque, Ana Christina Sagebin; Silva, Aliomar Gabriel da. Brasília. DF: Embrapa Informação Tecnológica, 2008.

CRESTANA, S.; MAGALHÃES, B. A cooperação técnica na política externa do Brasil em agricultura: o papel da Embrapa. Cooperação Técnica na Política Externa. Realizações e Desafios. Fundação Alexandre de Gusmão. Agência Brasileira de Cooperação. 2007. 15p.

DOSI, G. Technological paradigms and technological trajectories: a suggested interpretation of the determinants and directions of technical change. Research policy, v. 11, n. 3, p. 147-162, 1982.

EMBRAPA. Sugestões para formulação de um Sistema Nacional de Pesquisa Agropecuária. - Brasília, DF: Embrapa Informação Tecnológica, 2006.122 f. Edição especial do documento original (Livro Preto) preparado pelo Grupo de Trabalho, constituído pelo Ministro da Agricultura, Dr. Luiz Fernando Cirne de Lima, nos termos da Portaria ${ }^{\circ} 143$, de 18 de abril de 1972.

GONÇALVES, A.M. Fundos competitivos para o financiamento da pesquisa agrícola no Brasil: o caso do PRODETAB. Embrapa, 
2001. Disponível em: https://bit.ly/2YU5jgJ. Acesso em: 01 out. 2019.

HALL, P A.; TAYLOR, R. C. R. As três versões do neo-institucionalismo. Revista Lua Nova $\mathrm{N}^{\circ}$ 58, 2003.

HODGSON, G. M. "What Are Institutions?" Journal of Economic Issues Vol. XL No. 1. March 2006. Internacionais da FAAP. São Paulo, v. 6, n.12, p.103-116, Jan. 2008.

LOPES, M. Agricultural Research in Brazil - part V. 2010 Disponível em: https://bit. ly/3gBgsC6. Acesso em: 12 nov. 2019.

. Entrevista para Profa. Ana Célia Castro, para o INCT-PPED. 2012.

MAZZUCATO, M., O Estado Empreendedor: desmascarando o mito do setor público vs. setor privado. Editora Portfolio-Penguin, São Paulo, 2014.

MAZZUCATO, M.; PENNA, C.C.R. The Brazilian Innovation System: A MissionOriented Policy Proposal. Sumário Executivo. Avaliação de Programas em CT\&I. Apoio ao Programa Nacional de Ciência (Plataformas de conhecimento). Brasília, DF: Centro de Gestão e Estudos Estratégicos, 2016. Disponível em: https:// bit.ly/32IvSQj. Acesso em: 15 mai. 2019.

MENDES, P. J. \& ALBUQUERQUE, R. Instituições de Pesquisa Agrícola e Inovações Organizacionais: O Caso da Embrapa - Brasil. Anais do XII Seminário LatinoIberoamericano de Gestión Tecnológica - ALTEC, Buenos Aires, 2007. Disponível em: https://bit.ly/3gwAXji. Acesso em: 15 nov. 2019.

MENGEL, A.A.. Modernização da agricultura e pesquisa no Brasil: a Empresa Brasileira de Pesquisa Agropecuária - EMBRAPA . Tese (doutorado) - UFRRJ, Instituto de Ciências Humanas e Sociais. Rio de Janeiro/RJ, 2015.188 f.

MILANI, C.R.S.; PINHEIRO, L. (2013). Política Externa Brasileira: Os Desafios de sua Caracterização como Política Pública. In. Contexto Internacional. Rio de Janeiro, vol. $35, n^{\circ} 1$, janeiro/junho, p. 11-41.

NELSON, R R. \& WINTER, S. G. An evolutionary theory of economic change. Cambridge, Belnknap Press, 1985.
PENROSE, E. The theory of the firm. NYC: John Wiley \& Sons, 1959.

PIERSON, P.; SKOCPOL, T. El

Institucionalismo histórico en la ciencia política contemporânea. Revista Uruguaya de Ciencia Política[on-line] 17/12/2008. Disponível em: https://bit.ly/3b7pW7a. Acesso em: 4 abr. de 2019.

POSSAS, M.; SALLES-FILHO, S. \& SILVEIRA, J. An evolutionary approach to technological innovation in agriculture: some preliminary remarks. Research Policy $\mathrm{N}^{\circ}$ 25. Págs.: 933-945, 1996.

PROENÇA, A.. Capacitações Dinâmicas e o Dinamismo das Capacitações: enfoque centrado em Capacitações e o Processo Estratégico. 2003. Disponivel em: https:// bit.ly/3jbU97I. Acessado em: 25 ago. 2019. RADA, N.; VALDES, C. Policy, Technology, and Efficiency of Brazilian Agriculture, ERR-137, U.S. Department of Agriculture, Economic Research Service, July 2012.

ROYAL SOCIETY. New frontiers in science diplomacy: Navigating the changing balance of power. London, January/2010. Disponível em: https://bit.ly/3aZQJC3. Acesso em: 02 mar. 2019.

TEECE, D.; PISANO, G. The dynamic capabilities of the firms: an introduction. Industrial and Corporate Change, Oxford, 1994.

TEECE, D. ; PISANO, G. e SHUEN, A. Dynamic Capabilities and Strategic Management. Strategic Management Journal, v. 18, n. 7. (Aug., 1997), p. 509-533.

WINTER, S . Economic "Natural Selection" and the Theory of the Firm. In: Yale Economic Essays, 1964, pp 225-272 from Laboratory of Economics and Management (LEM), Sant'Anna School of Advanced Studies, Pisa, Italy.

WU, X.; MA, R.; XU, G. Secondary Innovation: The Experience of Chinese Enterprises in Learning, Innovation and Capability Building. National Natural Science Foundation Of China, 2013 (2006), Project 70272038. 